\title{
Role Of NIV In COPD Exacerbation One Year Experience From A Tertiary Care Hospital
}

\author{
Irfan Ahmed*, Javid Ahmad Wani\#, Showkat Ali Mufti† \\ *Senior Resident, \# Junior Resident, †Professor and Head \\ Department of Emergency Medicine, SKIMS, Srinagar, Jammu and Kashmir, India.
}

\section{A B S T R A C T}

\begin{abstract}
Introduction- Non-invasive ventilation (NIV) refers to delivery of mechanical ventilation with techniques that do not need an invasive endotracheal airway. The main indications are acute exacerbation of COPD, cardiogenic pulmonary edema, pulmonary infiltrates in immunecompromised patients, and weaning of previously intubated stable patients with COPD1. NIV has its best indication in moderate to severe respiratory acidosis in patients with AECOPD. For this indication, studies conducted in intensive care units (ICU's), in wards, and in Accident and Emergency Departments confirmed its effectiveness in preventing endotracheal intubation and reducing mortality?2.

Objectives- To see the outcome of NIV in patients of AECOPD with respiratory acidosis

Materials and Methods- The study was conducted in Department Of Emergency Medicine, Sher-i-Kashmir Institute of Medical Sciences, Soura, Srinagar, J and K, India over a period of one year from October 2015 to September 2016 during which 153 patients of AECOPD were treated with NIV.

Results- The study included 153 patients of AECOPD who received NIV, besides standard pharmacologic treatment. 124 (81.04\%) patients improved while as $29(18.96 \%)$ did not. The patients in the successful group experienced significant improvement in their $\mathrm{HR}, \mathrm{RR}, \mathrm{pH}, \mathrm{PaCO} 2$ and $\mathrm{PaO} 2$ from $116.2 \pm 12.3,32.4 \pm 4.3,7.27 \pm 0.06,80.7 \pm 12.5$, and $52.8 \pm 10.6$ at admission to $102.4 \pm 8.3,26.4 \pm 4.4,7.31 \pm 0.07,70.4 \pm 16.4$ and $58.6 \pm 11.5$, respectively, after 1 hour of NIV. This change in $\mathrm{HR}, \mathrm{RR}, \mathrm{pH}, \mathrm{PaCO} 2$ and $\mathrm{PaO} 2$ was statistically significant.

Conclusion- The study concludes that in patients with AECOPD with moderate- severe respiratory acidosis NIV should be the first line of treatment, besides the standard pharmacologic treatment. JMS 2016; 19(2):59-64.

Keywords- Non-invasive Ventilation (NIV), Chronic Obstructive Lung Disease (COPD), Acute Exacerbation of COPD (AECOPD), Bi-level Positive Airway Pressure (BPAP).
\end{abstract}

\section{INTRODUCTION}

Non-invasive ventilation (NIV) refers to delivery of mechanical ventilation with techniques that do not need an invasive endotracheal airway. ${ }^{1}$ NIV has a prominent role in acute respiratory failure. By avoiding endotracheal intubation, NIV prevents complications associated with invasive ventilation like airway problems, nosocomial pneumonia and sinusitis. In addition, the patient with an intact upper airway retains the ability to eat, swallow and verbalise $^{3-11}$. Use of NIV in appropriately selected patients of acute respiratory failure has impact on decreasing mortality, decreasing nosocomial infection, and decreasing Intubation

\section{Correspondence}

Dr. Showkat Ali Mufti,

Professor \& Head, Department of Emergency Medicine, SKIMS, Soura, Srinagar-190011, Jammu and Kashmir, E-Mail : showkatmufti@gmail.com rates $^{12-17}$. The main indications are acute exacerbation of COPD, cardiogenic pulmonary edema, pulmonary infiltrates in immune- compromised patients, and weaning of previously intubated stable patients with COPD1. Patients with severe acidosis or with altered level of consciousness due to hypercapnic acute respiratory failure are exposed to high risk of NIV failure. In these patients, NIV trial may be attempted in closely monitored clinical setting where proper endotracheal intubation may be assured ${ }^{2}$.

The interface used in NIV is a Mask of multiple tyes like Total Face Mask, Full Face Mask, Nasal Mask, Mouthpiece, Nasal Pillows And Helmet Mask. ${ }^{18}$

The ventilator used in NIV can be a standard ICU type ventilator or a portable one which can be run in different modes like Assist control, Pressure Support Ventilation, continuous positive airway pressure (CPAP) or bi- level 
airway positive pressure (BPAP). Bi-level positive airway pressure (BPAP) delivers both inspiratory positive airway pressure (IPAP) and expiratory positive airway pressure (EPAP). It is probably the most common mode used for NIV. The difference between the IPAP and EPAP is a reflection of the amount of pressure support ventilation provided to the patient, and EPAP is synonymous with positive end expiratory pressure (PEEP). ${ }^{19-21}$

Once a patient is selected to receive NIV, it should be initiated as soon as possible. Delay allows further deterioration and increase the likelihood of failure. ${ }^{22,23}$ The procedure is first explained to the patient, appropriate size interface is applied and starting pressures are set from low levels and adjusted as per patients tolerance. ${ }^{24} \mathrm{After}$ NIV is initiated, the patient should be observed closely for the first eight hours to troubleshoot, provide reassurance, and monitor for deterioration. Improvement of the $\mathrm{pH}$ and arterial carbon dioxide tension $(\mathrm{PaCO} 2)$ within one-half to two hours predicts success. ${ }^{25-27}$

Patients with COPD exacerbation and hypercapnic respiratory acidosis are the group most likely to be successfully treated with NIV. Exacerbations increase the work of breathing in these patients and may exceed the patient's ability to adequately ventilate. NIV effectively unloads the respiratory muscles, increasing the tidal volume, decreasing the respiratory rate, and decreasing the diaphragmatic work of breathing, which translates to an improvement in oxygenation, a reduction in hypercapnia, and an improvement in dyspnea. ${ }^{28}$

Clear cut evidence that NIV improves the outcomes in COPD exacerbations complicated by Hypercapnic respiratory acidosis. ${ }^{29-32}$

Meta-analysis of 14 Randomised Controlled Trials (RCT) (758 patients) compared standard medical therapy plus NIV with standard medical therapy alone.

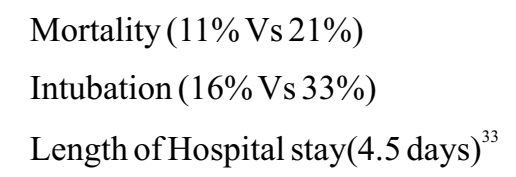

The benefit is most pronounced in patients with severe COPD exacerbation $(\mathrm{pH}<7.3)$.

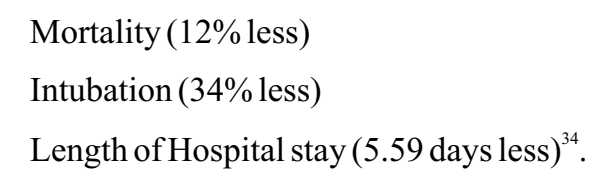

\section{Aims and Objectives}

To study the role and outcome of NIV in patients with AECOPD with respiratory acidosis.

\section{METHODS}

The study was conducted in the Department of Emergency Medicine, Sher-i-Kashmir Institute of Medical Sciences, Srinagar, Jammu and Kashmir, India over a period of one year from October 2015 to September 2016 during which 153 patients of AECOPD with respiratory acidosis were treated with NIV.

\section{Inclusion Criteria}

COPD patients with acute worsening of breathlessness with any one of the following

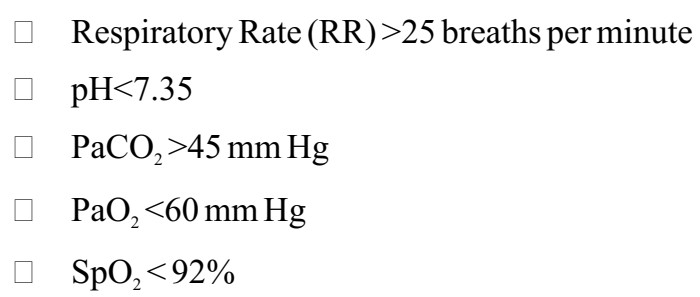

\section{Exclusion Criteria}

\author{
Cardiac arrest \\ Respiratory arrest \\ Upper Gastrointestinal Bleed \\ Shock \\ $\square$ Glasgow Coma Scale (GCS) $<8 / 15$ \\ $\square$ Recent Myocardial infarction \\ $\square \quad$ Copious respiratory secretions
}

\section{METHOD}

Once a patient fulfilled criteria for NIV, a baseline Heart Rate (HR), Respiratory Rate (RR), and Arterial Blood Gas $(\mathrm{ABG})$ analysis were taken, procedure explained to the patient and consent taken, NIV was administered by portable ventilator (Philips Respironics Triology 100) via Full face mask of appropriate size in BPAP mode in sitting position. Starting pressures were kept at IPAP 8 and EPAP 4 which were gradually titrated as per patient parameters. Patient would be observed throughout. ABG analysis repeated at 1 hour. If there was improvement in patients condition (clinical and laboratory parameters) NIV was continued. Weaning was considered when patient had persistent improvement. In case of worsening of patient's condition (lab or clinical), NIV was terminated and 
endotracheal intubation was considered.

\section{RESULTS}

In our study, the mean age of the patients was 65.4 years. 32 $(20.92 \%)$ patients were in $<60$ years age group while as 121 (79.08\%) patients belonged to the $>60$ years age group. Out of the 153 patients, $131(85.6 \%)$ were males and $22(14.4 \%)$ were females. NIV was successful in $124(81.04 \%)$ patients and failed in $29(18.96 \%)$ patients. Among the patients in successful group, $\mathrm{HR}, \mathrm{RR}, \mathrm{pH}, \mathrm{PCO}_{2}$ and $\mathrm{PO}_{2}$ at admission were $116.2 \pm 12.3,32.4 \pm 4.3,7.27 \pm 0.06,80.7 \pm 12.5$ and $52.8 \pm 10.6$ and changed to $102.4 \pm 8.3,26.4 \pm 4.4,7.31 \pm 0.07$,
$70.4 \pm 16.4$ and $58.6 \pm 11.5$ with 1 hour of NIV, respectively. This change in $\mathrm{HR}, \mathrm{RR}, \mathrm{pH}, \mathrm{PCO}_{2}$ and $\mathrm{PO}_{2}$ was statistically significant with $\mathrm{p}$-value $<0.05$. And, in the same group of patients, at discharge, $\mathrm{HR}, \mathrm{RR}, \mathrm{pH}, \mathrm{PCO}_{2}$ and $\mathrm{PO}_{2}$ were $84.1 \pm 6.2,21.4 \pm 4.5,7.39 \pm 0.05,58.2 \pm 10.8$ and $66.4 \pm 14.2$ respectively. While as, among the patients in the failed group, HR, RR, pH, $\mathrm{PCO}_{2}$ and $\mathrm{PO}_{2}$ were 120.4 \pm 8.5 , $36.6 \pm 6.5,7.25 \pm 0.05,88.4 \pm 14.4$ and $49.5 \pm 12.4$ at admission and after 1 hour of NIV changed to $116.2 \pm 7.2,30.1 \pm 4.3$, $7.25 \pm 0.06,83.5 \pm 11.7$ and $53.5 \pm 12.3$, respectively. This was not statistically significant. $10(6.5 \%)$ patients developed mucosal dryness as complication.

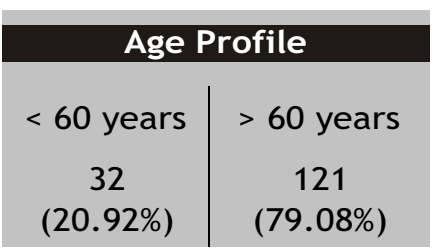

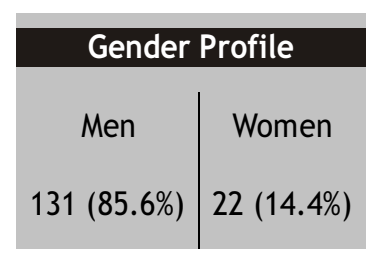

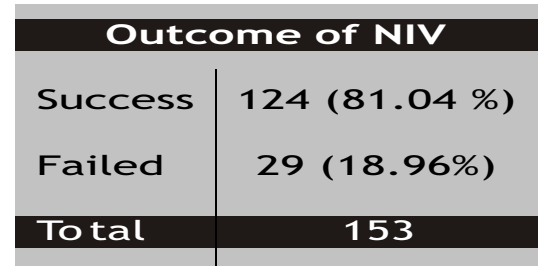

\begin{tabular}{|c|c|c|c|c|c|}
\hline \multicolumn{6}{|c|}{ Outcome of NIV } \\
\hline & \multicolumn{3}{|c|}{ Successful Group ( $n=124)$} & \multicolumn{2}{|c|}{ Failed Group (29) } \\
\hline & $\begin{array}{c}\text { At } \\
\text { admission }\end{array}$ & 1 hour & $\begin{array}{c}\text { At } \\
\text { discharge }\end{array}$ & $\begin{array}{c}\text { At } \\
\text { admission }\end{array}$ & 1 hour \\
\hline HR & $116.2 \pm 12.3$ & $102.4 \pm 8.3$ & $84.1 \pm 6.2$ & $120.4 \pm 8.5$ & $116.2 \pm 7.2$ \\
\hline RR & $32.4 \pm 4.3$ & $26.4 \pm 4.4$ & $21.4 \pm 4.5$ & $36.6 \pm 6.5$ & $30.1 \pm 4.3$ \\
\hline $\mathrm{pH}$ & $7.27 \pm 0.06$ & $7.31 \pm 0.07$ & $7.39 \pm 0.05$ & $7.25 \pm 0.05$ & $7.25 \pm 0.06$ \\
\hline $\mathrm{PaCO}_{2}$ & $80.7 \pm 12.5$ & $70.4 \pm 16.4$ & $58.2 \pm 10.8$ & $88.4 \pm 14.4$ & $83.5 \pm 11.7$ \\
\hline $\mathrm{PaO}_{2}$ & $52.8 \pm 10.6$ & $58.6 \pm 11.5$ & $66.4 \pm 14.2$ & $49.5 \pm 12.4$ & $53.5 \pm 12.3$ \\
\hline
\end{tabular}

\begin{tabular}{|c|c|c|c|}
\hline \multicolumn{4}{|c|}{ Successful group $(n=124)$} \\
\hline & At admission & 1 hour & $\mathrm{p}$ value \\
\hline HR & $116.2 \pm 12.3$ & $102.4 \pm 8.3$ & $<0.001$ \\
\hline RR & $32.4 \pm 4.3$ & $26.4 \pm 4.4$ & $<0.001$ \\
\hline $\mathrm{pH}$ & $7.27 \pm 0.06$ & $7.31 \pm 0.07$ & $<0.001$ \\
\hline $\mathrm{PaCO}_{2}$ & $80.7 \pm 12.5$ & $70.4 \pm 16.4$ & $<0.001$ \\
\hline $\mathrm{PaO}_{2}$ & $52.8 \pm 10.6$ & $58.6 \pm 11.5$ & $<0.001$ \\
\hline
\end{tabular}




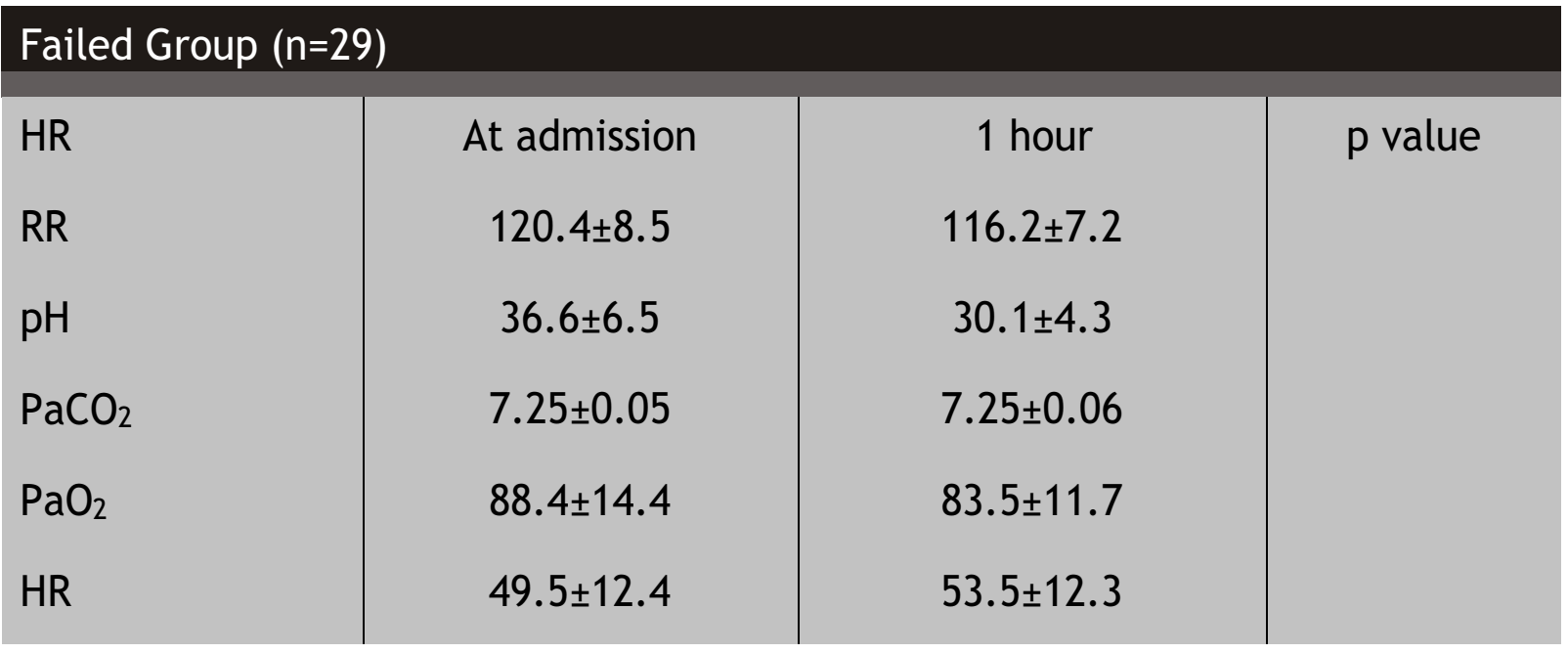

\section{Complications}

\section{Mucosal dryness}

$10(6.5 \%)$

\section{DISCUSSION}

In the present study, mean age of the patients was 65.4 years which is similar to other studies. ${ }^{35,36}$ Lt. Col S P Rai et al observed the mean age 68.32 years.

Gender distribution of the patients in the present study showed male predominance with $131(85.6 \%)$ males as against $22(14.4 \%)$ females which is consistent with other studies. ${ }^{36,37,38}$ In the study of Lt. Col S P Rai et al, males outnumbered the females.

Out of 153 patients in the study group, $124(81.04 \%)$ patients improved with NIV, while as $29(18.96 \%)$ patients failed to improve with NIV. Studies regarding NIV in AECOPD reveal around change in $\mathrm{HR}, \mathrm{RR}, \mathrm{pH}, \mathrm{PaCO}_{2}$ and $\mathrm{PaO}_{2}$ was statistically significant. This observation is consistent with other studies. Brochad et $\mathrm{al}^{29}$ found that RR and $\mathrm{pH}$ changed from $35 \pm 7$ to $25 \pm 8$ and $7.27 \pm 0.1$ to $7.31 \pm 0.09$, respectively, after 1 hour of NIV while as $\mathrm{PCO}_{2}$ change took 4 hours.

In our study, the patients in the successful group had their $\mathrm{HR}, \mathrm{RR}, \mathrm{pH}, \mathrm{PCO}_{2}$ and $\mathrm{PO}_{2}$ improved from 116.2 \pm 12.3 , $32.4 \pm 4.3,7.27 \pm 0.06,80.7 \pm 12.5$, and $52.8 \pm 10.6$ at admission to $84.1 \pm 6.2,21.4 \pm 4.5,7.39 \pm 0.05,58.2 \pm 10.8$ and $66.4 \pm 14.2$ at discharge, respectively. These results match with the results obtained by Verma et $\mathrm{al}^{39}$.

The patients of the failed group, in the present study, did not experience much improvement in their HR, RR, $\mathrm{pH}, 90 \%$ success rate. Verma et $\mathrm{ll}^{39}$ reported $\mathrm{PCO}_{2}$ and $\mathrm{Po}_{2}$ with 1 hour trial of NIV.a success rate of $90 \%$ with NIV in patients with AECOPD. In our study, the success rate is $81 \%$ which is less than that reported in the literature. We believe that the patients included in our study were more sick than the patients in other studies. The mean $\mathrm{pH}$ and $\mathrm{PaCO}_{2}$ of the patients in successful group in this study was $7.27 \pm 0.06$ and $80.7 \pm 12.5$ as against $7.33 \pm 0.08$ and $66.48 \pm 18.88$, respectively, in the study done by verma et $\mathrm{al}^{39}$.

In this study, the patients in the successful group experienced significant improvement in their HR, RR, $\mathrm{pH}$, $\mathrm{PaCO}_{2}$ and $\mathrm{PaO}_{2}$ from $116.2 \pm 12.3,32.4 \pm 4.3,7.27 \pm 0.06$, $80.7 \pm 12.5$, and $52.8 \pm 10.6$ at admission to $102.4 \pm 8.3$, $26.4 \pm 4.4,7.31 \pm 0.07,70.4 \pm 16.4$ and $58.6 \pm 11.5$, respectively, after 1 hour of NIV. Their $\mathrm{HR}, \mathrm{RR}, \mathrm{pH}, \mathrm{PCO}_{2}$ and $\mathrm{PO}_{2}$ were $120.4 \pm 8.5,36.6 \pm 6.5,7.25 \pm 0.05,88.4 \pm 14.4$ and $49.5 \pm 12.4$ at admission and after 1 hour of NIV changed to $116.2 \pm 7.2, \quad 30.1 \pm 4.3,7.25 \pm 0.06,83.5 \pm 11.7$ and $53.5 \pm 12.3$, respectively. This change in $\mathrm{HR}, \mathrm{RR}, \mathrm{pH}, \mathrm{PaCO}_{2}$ and $\mathrm{PaO}_{2}$ were not statistically significant. Garpestard et $\mathrm{al}^{40}$ had pointed out that patients not having a favourable initial response to NIV should be considered for intubation without delay. Following the failure to respond to NIV, they were considered for intubation.

In the present study, the mean duration of NIV use was 7.91 days which is comparable to other studies. Verma et $\mathrm{al}^{39}$ found the mean duration of NIV use in patients of AECOPD 8.35 days.

In the present study, $10(6.5 \%)$ patients developed mucosal 
dryness (mouth and nose) as a complication related to NIV. This is comparable to other studies ${ }^{41}$.

\section{CONCLUSION}

From the present study, we conclude that in patients of AECOPD with hypercapnic respiratory acidosis, NIV should be the first line of treatment, besides the standard pharmacologic treatment. However, NIV is not the panacea for all the AECOPD patients; if patient improves, don't stop to monitor; and if NIV fails, don't delay intubation.

\section{REFERENCES}

1. Ambrosino N, Vagheggini G. Noninvasive positive pressure ventilation in the acute care setting: where are we? European Respiratory Journal 2008; 31: 874886.

2. Nicolino Ambrosino, Guido Vagheggini. Noninvasive ventilation in exacerbations of COPD. Int $\mathrm{J}$ Chron Obstruct Pulmon Dis 2007; 2(4): 471476.

3. Burns KE, Sinuff T, Adhikari NK, Meade MO, HeelsAnsdell D, Martin CM, et al. Bilevel noninvasive positive pressure ventilation for acute respiratory failure: Survey of Ontario practice. Crit. Care Med 2005; 33: 1477-83.

4. Majid A, Hill N. Noninvasive ventilation for acute respiratory failure. Curr Opin Crit Care 2005; 11: 7781.

5. S Baudouin, S Blumenthal, B Cooper, C Davidson, A Davison, M Elliot, W Kinnear, R Paton, E Sawicka. Non-invasive ventilation for acute respiratory failure. Thorax 2002; 57: 192-211.

6. International Consensus Conferences in Intensive Care Medicine: Am J Respir Crit Care Med 2001; 163(1):283-91.

7. C Roussos, A Koutsoukou. Respiratory failure. European Respiratory Journal 2003; 22: 3s-14s.

8. Pingleton SK. Complications associated with mechanical ventilation. In: Tobin MJ (ed) Principles and Practice of Mechanical Ventilation. McGraw-Hill Inc, New York 1994; 775-792.

9. Torres A, Aznar R, Gatell JM, Jiménez P, González J, Ferrer A, Celis R, Rodriguez-Roisin R. Incidence, risk and prognosis factors of nosocomial, pneumonia in mechanically ventilated patients. Am Rev Respir Dis 1990; 142: 523-8.

10. Craven DE, Kunches LM, Kilinsky V, Lichtenberg DA, Make BJ, McCabe WR. Risk factors for pneumonia and fatality in patients receiving mechanical ventilation. Am Rev Respir Dis 1986; 133: 792-6.

11. Fagon JY, Chastre J, Hance AJ, Montravers P, Novara A, Gibert C. Nosocomial pneumonia in ventilated patients: A cohort study evaluating attributable morality and hospital stay. Am J Med 1993; 94: 281-2.

12. Demoule A, Girou E, Richard JC, Taille S, Brochard L. Benefits and risks of success or failure of noninvasive ventilation. Intensive Care Med 2006; $32: 17561765$.

13. Guérin C, Girard R, Chemorin C, De Varax R, Fournier G. Facial mask noninvasive mechanical ventilation reduces the incidence of nosocomial pneumonia. Intensive Care Med 1997; 23: 1024-1032.

14. Hess DR. Noninvasive positive-pressure ventilation and ventilator-associated pneumonia. Respir Care 2005; 50:9249.

15. Antonelli M, Conti G, Rocco M, Bufi M, De Blasi RA, Vivino G, Gasparetto A, Meduri GU. A Comparison of Noninvasive Positive-Pressure Ventilation and Conventional Mechanical Ventilation in Patients with Acute Respiratory Failure. N Engl J Med 1998; 339:429-435.

16. Girou E, Schortgen F, Delclaux C, Brun-Buisson C, Blot F, Lefort Y, Lemaire F, Brochard L. Association of noninvasive ventilation with nosocomial infections and survival in critically ill patients. JAMA 2000; 284(18): 2361-7.

17. Peter JV, Moran JL, Phillips-Hughes J, Warn D. Noninvasive ventilation in acute respiratory failure-a meta analysis update. Crit Care Med. 2002; 30(3):555-62.

18. Nava S, Navalesi P, Gregoretti C. Interfaces and humidification for noninvasive mechanical ventilation. Respir Care 2009; 54(1):71-84.

19. Liesching T, Kwok H, Hill NS. Acute applications of noninvasive positive pressure ventilation. Chest. 2003; 124(2):699713.

20. Kacmarek RM. Characteristics of pressure-targeted ventilators used for noninvasive positive pressure ventilation. Respir Care 1997; 42:380.

21. Ferguson GT, Gilmartin M. CO2 rebreathing during BiPAP ventilatory assistance. Am J Respir Crit Care Med 1995; 151(4):11261135.

22. Nava S, Navalesi P, Conti G. Time of non-invasive ventilation. Intensive Care Med. 2006; 32:36170. 
23. Early use of non-invasive positive pressure ventilation for acute exacerbations of chronic obstructive pulmonary disease: a multicentre randomized controlled trial. Chin Med J (Engl) 2005; 118(24):2034-40.

24. Stefano Nava, Nicholas Hill (2009). Non-invasive ventilation in acute respiratory failure, Respiratory intensive care unit; Lancet 2009; 374:250-59.

25. Kramer N, Meyer TJ, Meharg J, Cece RD, Hill NS. Randomized, prospective trial of non-invasive positive pressure ventilation in acute respiratory failure. Am J Respir Crit Care Med 1995; 151: 1799806.

26. Soo Hoo GW, Santiago S, Williams AJ. Nasal mechanical ventilation for hypercapnic respiratory failure in chronic obstructive pulmonary disease: determinants of success and failure. Crit Care Med 1994; 22(8):12531261.

27. Anton A, Guell R, Gomez J, Serrano J, Castellano A, Carrasco JL, Sanchis J. Predicting the result of noninvasive ventilation in severe acute exacerbations of patients with chronic airflow limitation. Chest; 117 (2000): 828-833

28. Keenan SP, Sinuff T, Cook DJ, Hill NS. Which patients with acute exacerbation of chronic obstructive pulmonary disease benefit from noninvasive positive-pressure ventilation? A systematic review of the literature. Ann Intern Med 2003; 138(11):861-70.

29. Brochard L, Mancebo J, Wysocki M, Lofaso F, Conti G, Rauss A, Simonneau G, Benito S, Gasparetto A, Lemaire F, et al. Noninvasive ventilation for acute exacerbations of chronic obstructive pulmonary disease. N Engl J Med 1995; 333(13): 817-22.

30. Ram FS, Picot J, Lightowler J, Wedzicha JA. Noninvasive positive pressure ventilation for treatment of respiratory failure due to exacerbations of chronic obstructive pulmonary disease. Cochrane Database Syst Rev 2004; (1):CD004104.

31. Keenan SP, Sinuff T, Cook DJ, Hill NS. Which patients with acute exacerbations of chronic obstructive pulmonary disease benefit from noninvasive positive pressureventilation? A systematic review of the literature. Ann Int Med 2003; 138:86170.

32. Keenan SP, Powers CE, McCormack DG. Noninvasive positive-pressure ventilation in patients with milder chronic obstructive pulmonary disease exacerbations: a randomized controlled trial. Respir Care 2005; 50:610616.

33. Ram FS, Picot J, Lightowler J, Wedzicha JA. Noninvasive positive pressure ventilation for treatment of respiratory failure due to exacerbations of chronic obstructive pulmonary disease. Cochrane Database Syst Rev 2004; (1):CD004104.

34. Keenan SP, Powers CE, McCormack DG. Noninvasive positive-pressure ventilation in patients with milder chronic obstructive pulmonary disease exacerbations: a randomized controlled trial. Respir Care 2005; 50:610616.

35. George IA, John G, John P, Peter JV, Christopher S. An evaluation of the role of non-invasive positive pressure ventilation in the management of acute respiratory failure in a developing country. Indian J Med Sci 2007; 61: 495-504.

36. Lt Col S P Rai, Brig B N Panda, Lt. Col K. K. Upadhyay. Non-invasive Positive Pressure Ventilation in Patients with Acute Respiratory Failure. MJAFI 2004; 60(3): 224-26.

37. Vanani V, Patel M. A study of patients with type II respiratory failure put on non-invasive positive pressure ventilation. Ann Trop Med Public Health 2013; 6:369-77.

38. MA Soliman, MI El-Shazly, YMA Soliman, AI Mostafa. Effectiveness of non-invasive positive pressure ventilation in chronic obstructive pulmonary disease patients. Egyptian journal of chest diseases and Tuberculosis 2014: 309-312.

39. Ajay Verma, Mayank Mishra, Surya kant, Anand Kumar, Sushil K Verma, Sudhir Chaudhri, J Prabhuram. Noninvasive mechanical ventilation: An 18-month experience of two tertiary care hospitals in north India. Lung India 2013: 307-311.

40. Garpested E, Brennan J, Hill SN. Non-invasive ventilation for critical care. CHEST 2007, 132: 71120 .

41. G Umberto Meduri, Robert E Turner, Nabil AbouShala, Richard Wunderink, Elizabeth Tolley. Noninvasive Positive Pressure Ventilation via Face Mask: First-Line Intervention in Patients with Acute Hypercapnic and Hypoxemic Respiratory Failure. Chest 1996; 109(1): 179-193. 